\title{
DEVELOPMENT OF HOT BAND ANNEALING TEXTURE IN AUSTENITIC STAINLESS STEEL
}

\author{
C. D. SINGH \\ Research and Development Centre for Iron and Steel, Steel Authority of India \\ Limited, Ranchi-834002, India
}

(Received 10 November 1995)

\begin{abstract}
The microstructural and textural analysis of the hot band reveals that the surface grains are fully recrystallised and possess the orientation elements of the shear texture, distributed along $<110>/ / \mathrm{RD}$ and $<110>30^{\circ} \mathrm{ND}$ fibres, while the grains, in the central layer, are partially recrystallised and their texture is composed of orientation elements of recrystallisation texture $(<100>/ / R D)$ and of coppertype texture $\left(<110>60^{\circ} \mathrm{ND}\right)$, with $\{001\}<100>$ and $\{011\}<112>$ as the major components, respectively. The other interesting feature of the hot band microstructure is the formation of recovery twins in the grains of $\{011\}<112>$. The short time annealing of the hot band leads to the formation of annealing twins in addition to the growth of the surface grains and to the complete recrystallisation of the grains in the central layers. Many physical processes such as the growth of the recovery twins and of the grain boundary nucleated grains contribute to the development of final annealing textures of the annealed hot band, which are like the textures present in the surface and the central layers of the hot band.
\end{abstract}

KEY WORDS: Annealing twins, recovery twins, recrystallisation texture, shear texture, copper-type texture, oriented nucleation.

\section{INTRODUCTION}

In the last few decades, the development of annealing (i.e. recrystallisation) textures in F.C.C. metals and alloys has been the subject of numerous investigations (Burgers, 1949; Beck, 1954; Burgers and Tiedema, 1957; Dillamore and Roberts, 1965; Beck and Hu, 1966; Grewen, 1971; Guttman, 1973; Hutchinson, 1974) and many International Conferences on texture of materials (Grewen and Wassermann, 1969; Karp et al., 1971; Penelle, 1973; Davies et al., 1975; Gottstein and Lücke, 1978; Nagashima, 1981; Brakman, Jongenburger and Mittemeiger, 1984; Kallend and Gottstein, 1988; Bunge, 1991; 1993). Most of these studies, depending upon stacking fault energy (SFE) and degree of cold reduction of materials, indicate that the origin of annealing textures can be attributed to the theory of oriented nucleation (Burgers and Louwerse, 1931; Burgers and Tiedema, 1953; Verbraak, 1958; Dillamore and Katoh, 1974b) or to that of oriented growth (Beck and $\mathrm{Hu}, 1966$; Lücke, 1974). Another mechanism, producing generally new orientations, is the recrystallisation twinning which involves nucleation and then growth events and thus leads to the formation of annealing twins in the recrystallised microstructure of materials with low SFE. Most recently, the very incipient stage of this nucleation event has been recognised as recovery twins (Huber and Hatherly, 1979; 1988) and evidences are getting accumulated for the creation of such twins through recovery process in the regions of brass-type shear bands and copper-type microbands of heavily deformed materials. On the other hand, Verbraak (1981) has suggested that 
the formation of recovery twins is a low SFE equivalent of polygonisation in high SFE materials and it requires the annihilation of excess dislocations within the deformation twins by partial dislocations piled up in between twins and crossing the twin boundaries during heating and thus creates the recovery twins. There are, however, no reported evidence of recovery twins in hot band (HB) materials such as austenitic stainless steel in which deformation, dynamic recovery and dynamic recrystallisation play a complex role during hot rolling. Furthermore, the effect of short time annealing on the development of annealing texture in hot band is also clearly not known.

Knowledge of orientations of recovery twins and of matrix texture components present near the surface and the central layers should contribute to the understanding of the annealing texture development in hot band. It is now clear that the textures evolved during hot rolling of most F.C.C. metals and alloys can be understood on the basis that the surface and sub-surface regions are subjected to a redundant shear-strain deformation whereas the interior layers undergo a plain-strain deformation. Accordingly, the hot rolled strip acquires components of shear texture or rolling texture and above all, the temperature of deformation at different layers determines the state and the orientation of grains (i.e. recovered, recrystallised or a mixture of deformation and recrystallisation). The most recent investigation (Singh, Ramaswamy and Suryanaryana, 1991) on the texture evolution in an austenitic stainless steel hot band indicates that the surface texture is composed of the orientation elements of shear texture. These elements are mainly distributed along two limited tubes of preferred orientations. The fibre of the first orientation tube has its axis $<110>/ / \mathrm{RD}$ and stretches from $\{001\}<110>$ to an orientation near $\{112\}<110>$ while that of the second tube is inclined $30^{\circ}$ from ND towards RD (i.e. $<110>30^{\circ} \mathrm{ND}$ fibre) and runs from an orientation near $\{112]<110>$ to the orientation near $\{111\}<112>$. On the contrary, a duplex texture consisting of orientation components of retained rolling texture (copper-type) and recrystallisation texture $(\{001\}<100>)$ is present at the central layer of the hot band. The copper-type texture is usually described by $<110>60^{\circ} \mathrm{ND}$ fibre extending from $\{112\}<111>$ through $\{123\}<634>$ to $\{011\}<112>$ with $\{112\}<111>$ or $\{123\}<634>$ as a major component.

The aim of the present paper is to describe an investigation on the nature of the processes involved in the development of annealing texture in the hot band of an austenitic stainless steel during short time annealing. The rolling, transverse and normal directions of the strip are denoted by RD, TD and ND respectively.

\section{EXPERIMENTAL PROCEDURE}

Starting material was a hot band (HB) of commercially produced austenitic stainless steel (i.e. AISI 304) of nominal composition (by wt\%): $19.25 \% \mathrm{Cr}, 8.40 \% \mathrm{Ni}, 0.05 \% \mathrm{C}$, $1.24 \% \mathrm{Mn}, 0.48 \% \mathrm{Si}, 0.02 \% \mathrm{P}$ and $0.02 \% \mathrm{~S}$. According to supplier's information, the $2.95 \mathrm{~mm}$ thick HB strip was finished at about $1173 \mathrm{~K}$ and coiled at about 1023K. Part of the material used for investigation was in the form of annealed hot band (AHB). This AHB strip was produced by solution annealing the HB at $1353 \mathrm{~K}$ for 5 minutes and then quenching into water. Both $\mathrm{HB}$ and $\mathrm{AHB}$ strips were pickled in pickling solution (by vol.\%) of $10 \% \mathrm{HNO}_{3}+2 \% \mathrm{HF}+88 \%$ water at a temperature $323 \mathrm{~K}$ for a period of 5 minutes for the removal of any oxides and scales on the surfaces.

Microstructural examinations were performed by optical microscopy on specimens of both $\mathrm{HB}$ and AHB mechanically polished and electrolytically etched in saturated oxalic acid solution at 10 volts for 2 minutes at sections $(S=1, S=0)$ cut perpendicular 
to the transverse direction containing RD and ND (i.e. longitudinal sections). Here, $S=1$ and $S=0$ denote the surface and the mid thickness of the specimen, respectively. The hardness of the specimens was determined for $S=1$ and $S=0$ levels at the sections cut parallel to the rolling plane using a $5 \mathrm{~kg}$ load on a standard Vickers hardness tester.

Transmission electron metallography (TEM) was carried out on thin foils of HB and AHB at $S=0$ level in which the plane of the foil was parallel to the rolling plane of the strip. After chemically thinning the strip to $0.1 \mathrm{~mm}$ in a boiling solution (vol.\%) of $45 \%$ water, $30 \% \mathrm{HNO}_{3}, 15 \% \mathrm{Hcl}$ and $10 \% \mathrm{HF}$ and punching to $3 \mathrm{~mm}$ dia. discs, the thin foils were produced using a TENUPOL electrolytic twin jet polisher operated at $40 \mathrm{~V}$ and $0.14 \mathrm{~A}$ with an electrolyte $(\mathrm{Vol} \%)$ consisting of $5 \%$ perchloric acid in acetic acid. The thin foils were examined in a JEOL 4000E microscope at an accelerating voltage of $300 \mathrm{KV}$. Local orientations of recrystallised grains of $\mathrm{HB}$ and AHB were determined by electron diffraction in order to investigate the origin and formation of annealing textures.

X-ray texture measurements were performed for both HB and AHB materials at the sections ( $S=1$ and $S=0$ levels) parallel to the rolling plane on an automatic texture goniometer fitted with SIEMENS D500 diffractometer, using $\mathrm{M} 0_{\mathrm{K} \alpha}$ radiation. For each ground and etched specimen $(20 \mathrm{~mm} \times 14 \mathrm{~mm})$, the texture was determined by measuring four incomplete pole-figures of the planes $\{111\},\{200\},\{220\}$ and $\{113\}$, using the Schulz back reflection technique (Schulz, 1949). For each measurement, the diffracted intensity was recorded continuously every $5^{\circ}$ along concentric circles in the angular range from $0^{\circ}$ to $75^{\circ}$ in steps of $5^{\circ}$ and subjected to background, geometrical and defocussing corrections using a random specimen of pressed and sintered austenitic stainless steel powders. The three dimensional orientation distribution functions (ODF) was calculated from the data of four incomplete pole-figures following the series expansion method (Bunge, 1982) and using the pseudo-normalisation technique (Kern and Bergmann, 1978). The series was extended upto $1=22$ using even terms only. The texture index, $J$, which determines the mean square deviation of the ODF from random distribution, was also determined in each case.

Due to cubic crystal and orthorhombic sample symmetry, a general orientation possesses 96 symmetrical equivalent positions in Euler angular space. The Euler space $\left(0^{\circ} \leq \phi_{1}, \phi, \phi_{2} \leq 90^{\circ}\right)$ used in the present investigation contained each orientation three times each in three basic ranges. The measured ODF $f(g)$ was presented in the form of isointensity contour lines corresponding to multiples of random orientation density in section $\phi_{1}$, or $\phi_{2}=$ constant $\left(0^{\circ}, 5^{\circ}, 10^{\circ}\right.$, $\left.9^{\circ}\right)$ through this Euler angle space. Although the ODFs which will be discussed contain ghost errors (Matthies, 1979; Lücke et al., 1981), they are sufficiently small so as not to affect the interpretation of the principal results. The obtained ODFs exhibit maxima of orientations. While exact orientations of maxima are listed in the tables, in the text approximate orientations are used (indicated by $\approx$ ) if the indices are clearly simpler.

\section{EXPERIMENTAL RESULTS}

\section{Hot Band (HB)}

\section{Microstructure}

The as-received hot band was fully austenitic because the X-ray diffractogram did not show any phase other than austenite reflections (Singh, 1989). The optical micrograph 
of the HB longitudinal section near the surface $(S=1)$ is shown in Figure 1(a). This figure indicates the presence of equiaxed grains mostly nucleated at the pre-existing grain boundaries as well as of some within the volume of banded regions. Some of the recrystallised grains are in elongated shape. On the other hand, a heavily deformed (i.e. elongated) regions along with a few recrystallised grains are evident in the optical micrograph of the central layers $(S=0)$ of the HB [Figure 1(b)]. The preferentially etched dark bands in the above micrographs appear to be thin sheet like bands of heavily deformed austenite grains. The hardness values measured on the rolling plane sections near the surface and at the central layers were about $235 \mathrm{HV}_{5}$ and $269 \mathrm{HV}_{5}$ respectively whereas the average grain sizes determined on the same sections were about $7 \mu \mathrm{m}$.

The TEM microstructural features observed near the central level of $\mathrm{HB}$ are given in Figure 2. The presence of very fine recovery twins and recovered regions is clearly revealed in the bright field image [Figure 2(a)]. The selected area diffraction pattern (SADP) associated with the twin-matrix region is of $\{011\}<112>$ type and given in Figure 2(b) while Figure 2(c) illustrates the indexing of the SADP. The twins varied in length from $1.6 \mu \mathrm{m}$ to $3.6 \mu \mathrm{m}$ and were less than $0.015 \mu \mathrm{m}$ thick. Only one set of the twins was observed. It is also apparant from Figure 2(a) that the region in which the twins formed is clearly distinguishable from the regions (upper and lower parts) containing structureless features. These structureless regions are associated with $\{011\}<100>$ type diffraction pattern. Furthermore, strain free grains have nucleated at the grain boundary.

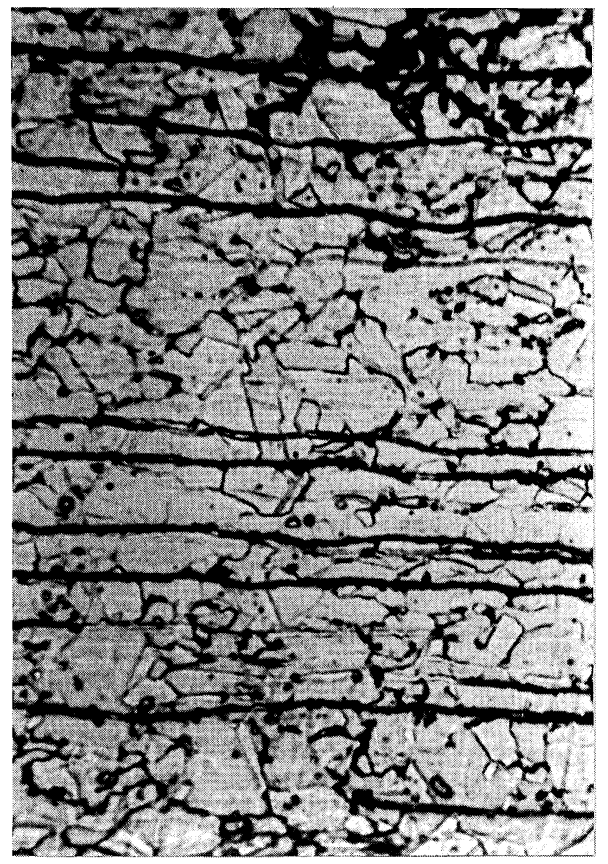

a

$20 \mu \mathrm{m}$

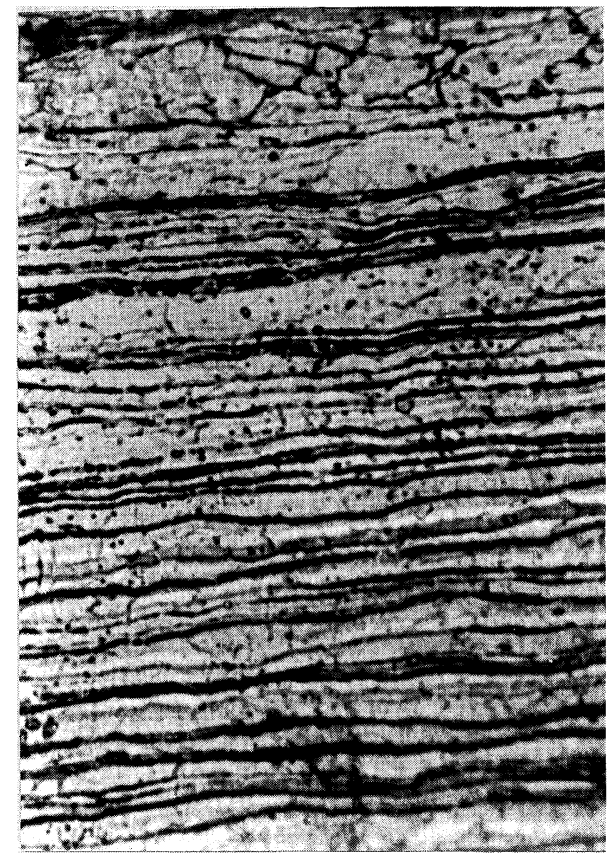

b

Figure 1 Optical micrographs of longitudinal section of the hot band: (a) near surface (b) at Centre: arrow parallel to rolling direction. 


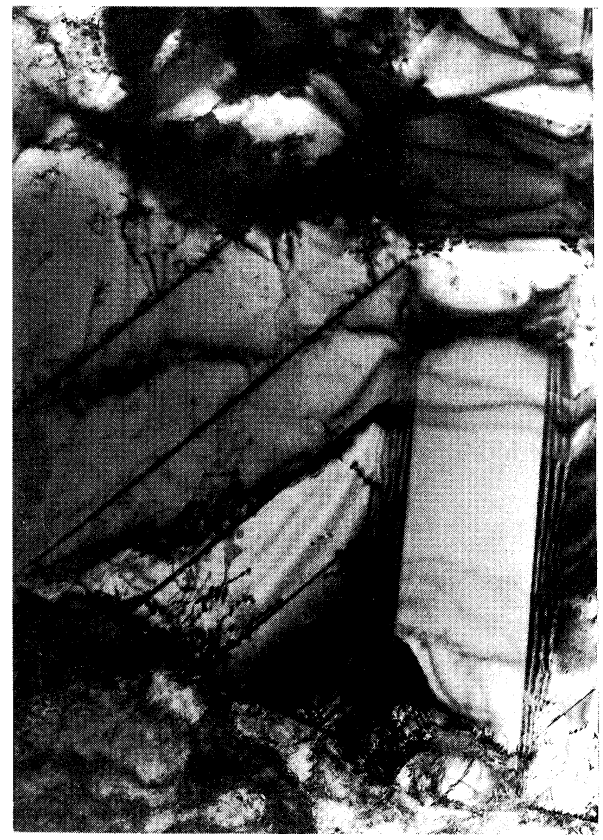

a

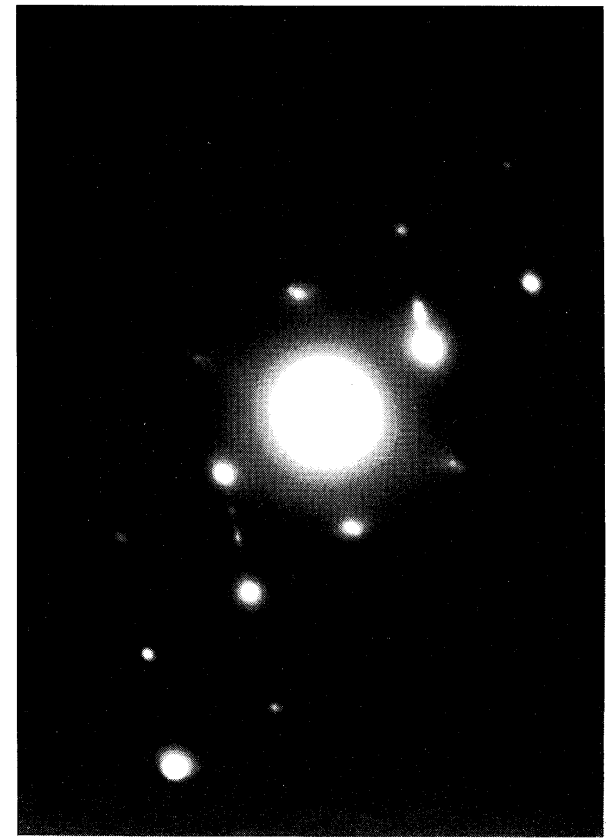

b

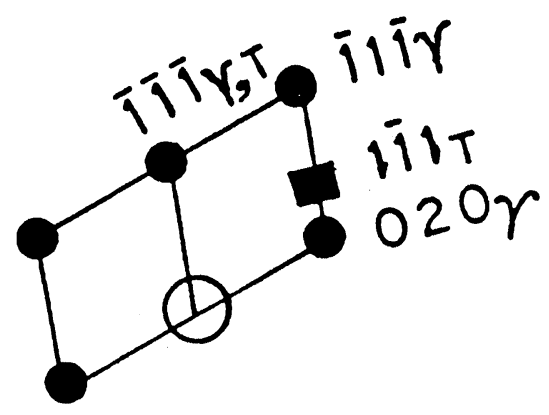

c

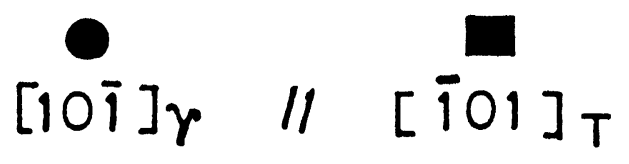

Figure 2 Transmission electron micrographs of the central layer of the hot band: (a) bright field image (b) selected area diffraction pattern (SADP) (c) indexing of the SADP. 


\section{Texture}

The ODF of crystallites near the surface $(S=1)$ of the HB in constant $\phi_{1}$ sections is shown in Figure 3. This ODF exhibits maxima for orientations which are given in Table 1 along with their Euler angles $\left(\phi_{1}, \phi, \phi_{2}\right)$. The texture component $\begin{cases}7 & 12\}<110>\end{cases}$ which is about $5^{\circ}$ away from the ideal orientation $\{112\}<110>$, rotated about $R D$, shows the maximum density. The other texture components present on the surface of the HB are mainly $\{118\}<110>(\approx\{001\}<110>),\{332\}<110>(\approx\{111\}<110>)$,
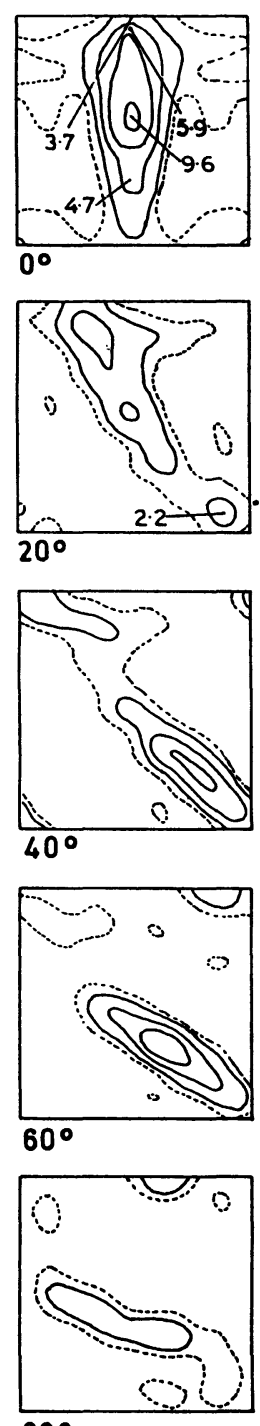

$80^{\circ}$
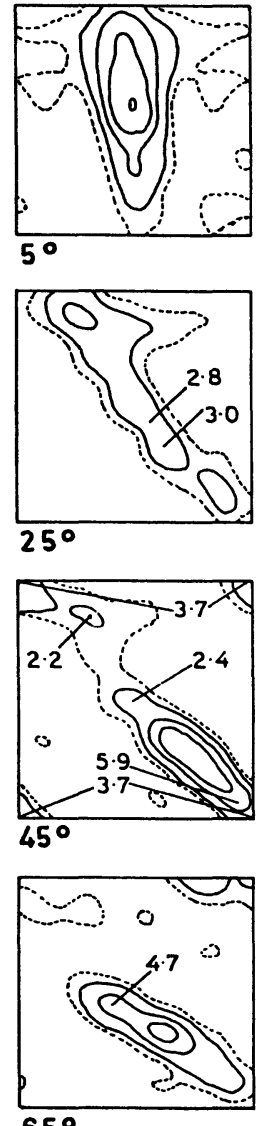

$65^{\circ}$

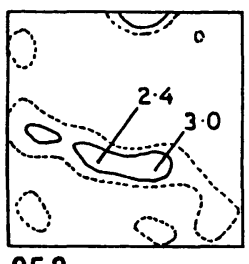

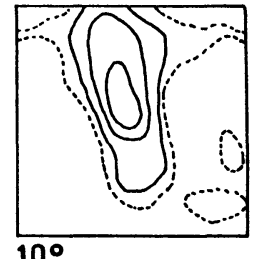

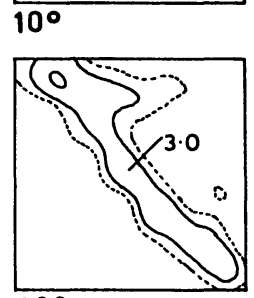

$30^{\circ}$
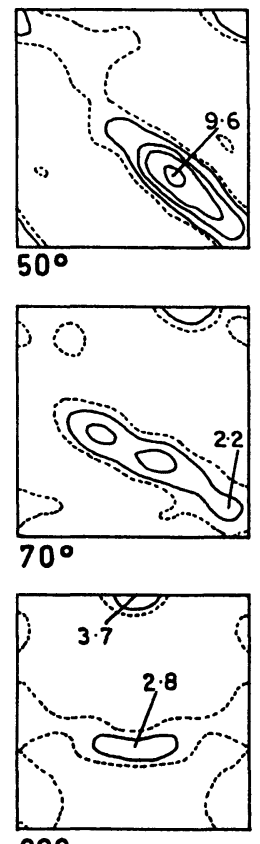

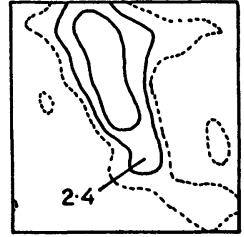

$15^{\circ}$
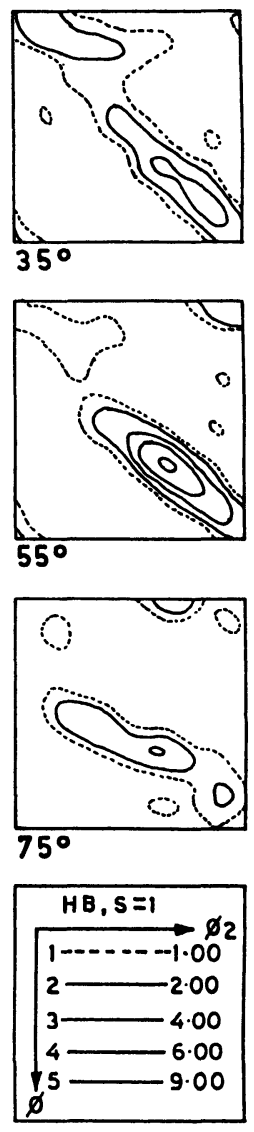

Figure 3 ODF for surface $(S=1)$ level of the hot band in constant $\varnothing_{1}$ sections. 
Table 1 Orientation Density $\mathrm{f}(\mathrm{g})$ of the Texture Components $\{\mathrm{hkl}\}<\mathrm{uvw}>$ near the surface of Hot Band (HB) and Annealed Hot Band (AHB).

\begin{tabular}{|c|c|c|c|c|c|c|}
\hline \multirow[t]{2}{*}{$h k l$} & \multirow[t]{2}{*}{$u v w$} & \multicolumn{3}{|c|}{ Euler Angles } & \multicolumn{2}{|c|}{$\begin{array}{l}\text { Orientation } \\
\text { Density } f(g)\end{array}$} \\
\hline & & $\phi_{1}$ & $\phi$ & $\phi_{2}$ & $H B$ & $A H B$ \\
\hline$\{001\}$ & $<110>$ & 0 & 0 & 45 & 3.7 & 1.4 \\
\hline$\{118\}$ & $<110>$ & 0 & 10 & 45 & 5.9 & 2.9 \\
\hline \multirow{2}{*}{$\begin{array}{l}\left\{\begin{array}{lll}7 & 7 & 12\end{array}\right\} \\
\text { (equal to) } \\
\{112\}\end{array}$} & $<110>$ & 0 & 40 & 45 & \multirow[t]{2}{*}{9.6} & \multirow[t]{2}{*}{6.2} \\
\hline & $<110\rangle$ & 0 & 35 & 45 & & \\
\hline \multirow{2}{*}{$\begin{array}{l}\{332\} \\
\text { (equal to) } \\
\{111\}\end{array}$} & $<110>$ & 0 & 65 & 45 & \multirow[t]{2}{*}{4.7} & \multirow[t]{2}{*}{1.9} \\
\hline & $<110\rangle$ & 0 & 55 & 45 & & \\
\hline \multirow{2}{*}{$\begin{array}{l}\{111\} \\
\text { (equal to) } \\
\{111\}\end{array}$} & $<112\rangle+5^{\circ}$ & 90 & 60 & 45 & \multirow[t]{2}{*}{2.8} & \multirow[t]{2}{*}{1.6} \\
\hline & $<112>$ & 90 & 55 & 45 & & \\
\hline$\{232\}$ & $<225>$ & 84 & 61 & 56 & 3.0 & 2.1 \\
\hline \multirow{2}{*}{$\begin{array}{l}\left\{\begin{array}{lll}9 & 12 & 8\end{array}\right\} \\
\text { (equal to) } \\
\left\{\begin{array}{ll}111\end{array}\right\}\end{array}$} & $<3712>$ & 84 & 58 & 34 & \multirow[t]{2}{*}{2.4} & \multirow[t]{2}{*}{1.7} \\
\hline & $<123>$ & 79 & 55 & 45 & & \\
\hline \multirow{2}{*}{$\begin{array}{l}\{129\} \\
\text { (equal to) } \\
\{139\}\end{array}$} & $<4 \quad 112>$ & 44 & 14 & 27 & \multirow[t]{2}{*}{2.2} & \multirow[t]{2}{*}{2.2} \\
\hline & $<341>$ & 36 & 19 & 18 & & \\
\hline
\end{tabular}

$\{111\}<112>+5^{\circ}(\approx\{111\}<112>)$ and $\left\{\begin{array}{lllll}9 & 12 & 8\end{array}\right\}<3 \quad 7 \quad 12>(\approx\{111\}<123>)$ in the decreasing order of orientation density. The most concise though not complete representation of the components of the surface texture in $\phi_{2}=45^{\circ}$ section is presented in Figure 4. It is clearly evident from this figure that there are two limited tubes of
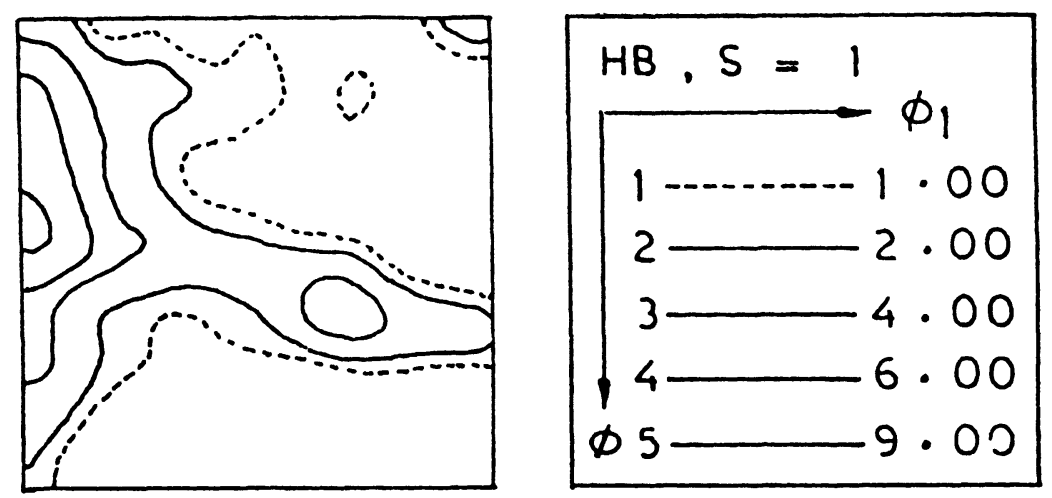

Figure 4 Section $\varnothing_{2}=45^{\circ}$ of the ODF for surface $(S=1)$ level of the hot band. 
preferred orientations in an orientation space. One of the orientation tube has its $<110\rangle$ fibre axis parallel to $\mathrm{RD}(<110>/ / \mathrm{RD})$ and stretches from an orientation $\{001\}<110>$ to $\approx\{112\}<110>$ with the maximum at $\approx\{112\}<110>$. Further this tube extends towards $\{111\}<110\rangle$. The second orientation tube has it $\langle 110\rangle$ fibre axis inclined about $30^{\circ}$ from ND towards $\mathrm{RD}\left(<110>30^{\circ} \mathrm{ND}\right)$ and runs from $\approx\{111\}<112>$ to $\approx\{112\}<110>$. The orientation densities along the skeleton line of the above two tubes have been shown in Figures 5 and 6, respectively. It becomes clearly evident from Figure 5 that the

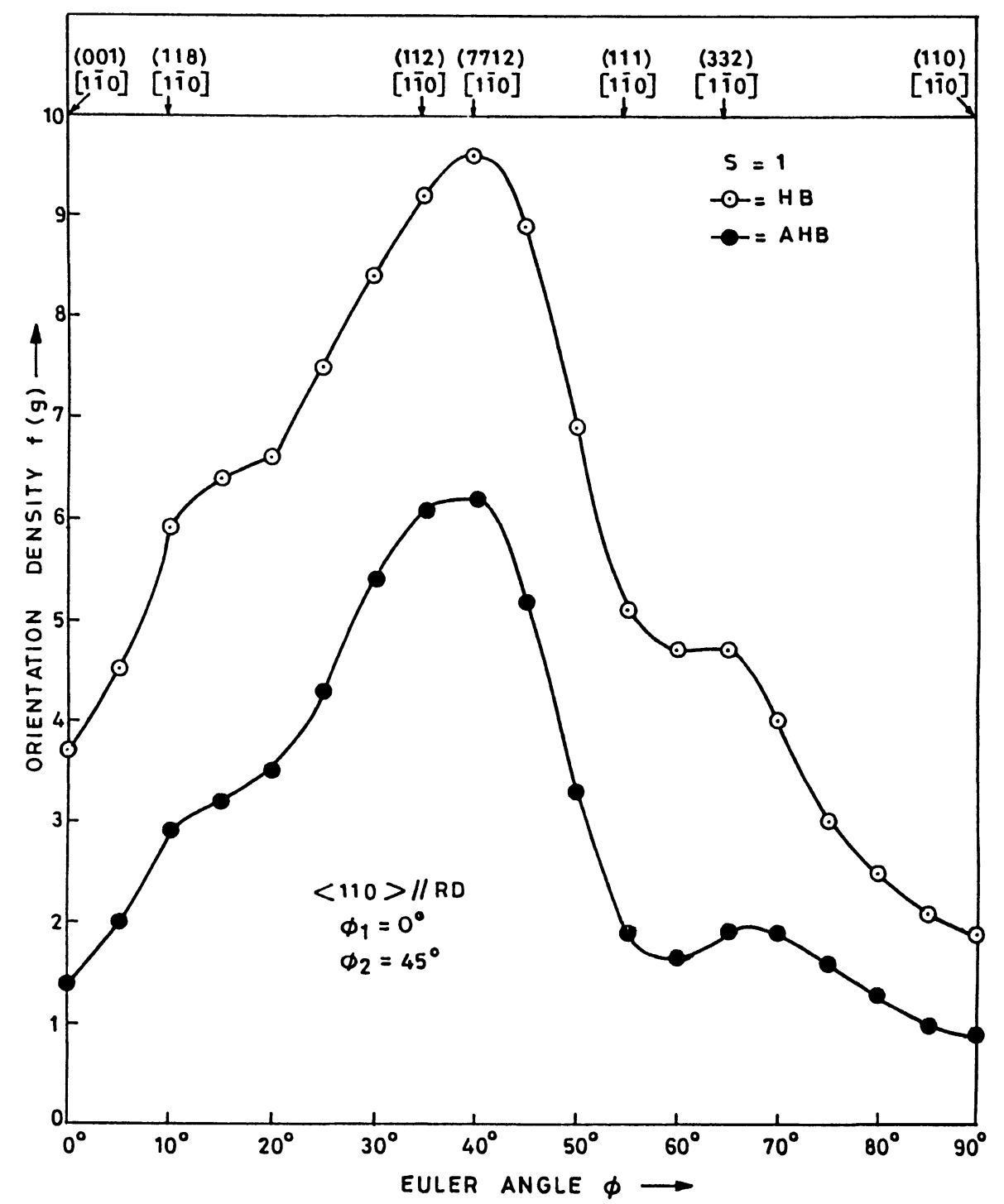

Figure 5 Orientation densities along $<110>/ / R D$ fibre for the surface $(S=1)$ level of the hot band and the annealed hot band. 
texture profile along $\{110\} / / \mathrm{RD}$ fibre contains a strong peak near $\{112\}<110>$ along with two concealed peaks near $\{118\}<110>$ and $\{332\}<110>$ and also a minor peak at $\{001\}<110>$. On the other hand, Figure 6 indicates that the density value $f(g)$ along $<110>30^{\circ} \mathrm{ND}$ fibre increases strongly in the orientations $\approx\{112\}<110>$. The texture index $\mathrm{J}$ determined near the surface was 3.0.

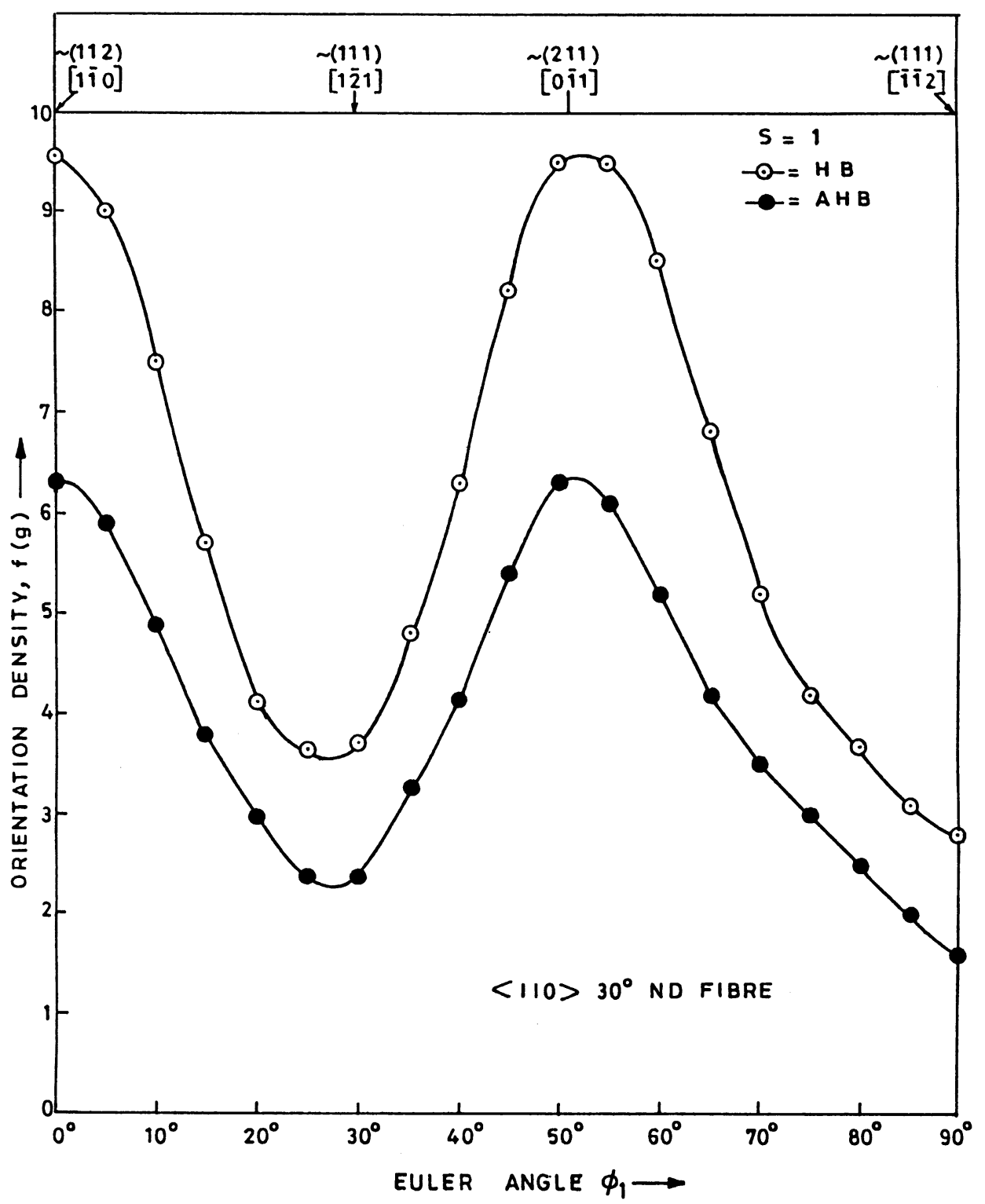

Figure 6 Orientation densities along the skeleton line of $<110>30^{\circ} \mathrm{ND}$ fibre for the surface $(\mathrm{S}=1)$ level of the hot band and the annealed hot band. 
The ODF of crystallites in constant $\phi_{2}$ sections and the maxima for orientations at the central layer are presented in Figure 7 and Table 2 respectively. The most interesting feature of this ODF is the presence of components of recrystallisation as well as the copper-type rolling textures. The cube orientation $\{001\}<100>$ and the RD rotated cubes in between the cube position $\left(\phi_{1}=\phi=\phi_{2}=0^{\circ}\right)$ and the Goss position $\left(\phi_{1}=\phi_{2}=\right.$ $\left.0^{\circ}, \phi=45^{\circ}\right)$ are the elements of recrystallisation texture with the cube orientation as

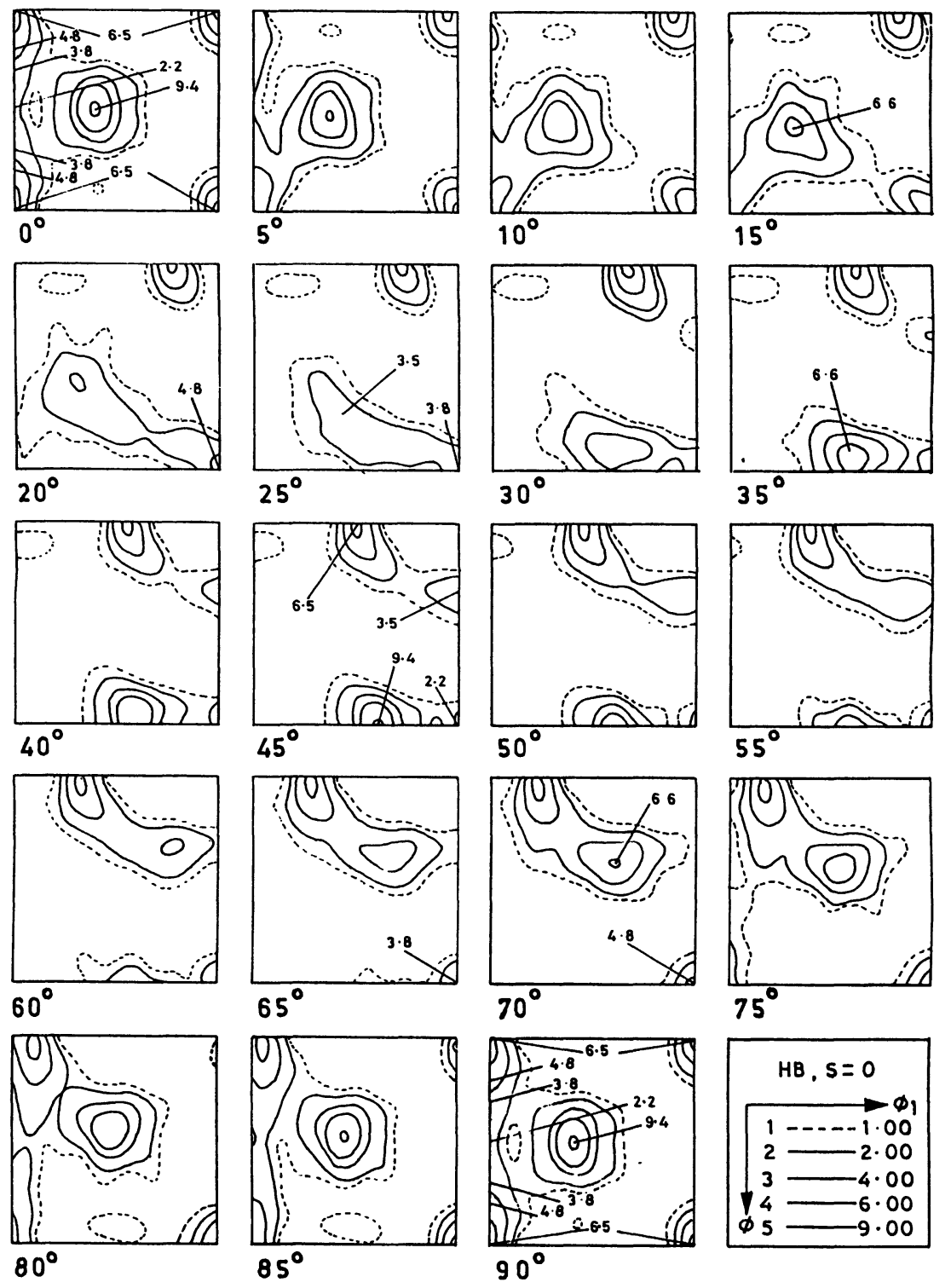

Figure 7 ODF for centre $(S=0)$ level of the hot band in constant $\varnothing_{2}$ sections. 
Table 2 Orientation Density $f(g)$ of the Texture Components $\{h k l\}<u v w>$ at the Centre of Hot Band (HB) and Annealed Hot Band (AHB)

\begin{tabular}{|c|c|c|c|c|c|c|}
\hline \multirow[t]{2}{*}{$h k l$} & \multirow[t]{2}{*}{$u v w$} & \multicolumn{3}{|c|}{ Euler Angles } & \multicolumn{2}{|c|}{$\begin{array}{c}\text { Orientation } \\
\text { Density } f(g)\end{array}$} \\
\hline & & $\phi_{1}$ & $\phi$ & $\phi_{2}$ & $H B$ & $A H B$ \\
\hline $\begin{array}{l}\text { Copper-type Rolling } \\
\{011\}\end{array}$ & $\begin{array}{l}\text { Texture } \\
<112>\end{array}$ & 35 & 45 & 0 & 9.4 & 6.6 \\
\hline$\{134\}$ & $<956>$ & 54 & 38 & 72 & 6.6 & 4.9 \\
\hline$\{123\}$ & $<634>$ & 59 & 37 & 63 & & \\
\hline$\{112\}$ & $<111>$ & 90 & 35 & 45 & 3.5 & 2.4 \\
\hline $\begin{array}{l}\text { Recrystallised Texture } \\
\{001\}\end{array}$ & $<100>$ & 0 & 0 & 0 & 6.5 & 6.1 \\
\hline$\{013\}$ & $<100\rangle$ & 0 & 18 & 0 & 4.8 & 3.7 \\
\hline$\{012\}$ & $\langle 100\rangle$ & 0 & 27 & 0 & 3.8 & 3.2 \\
\hline$\{011\}$ & $<100>$ & 0 & 45 & 0 & 2.2 & 2.0 \\
\hline$\{011\}$ & $<111>$ & 55 & 45 & 0 & - & 2.9 \\
\hline$\{011\}$ & $<411>$ & 19 & 45 & 0 & - & 2.9 \\
\hline
\end{tabular}

major component. Figure 8 illustrates the density distribution of all the orientations of recrystallised texture along $<100>/ / \mathrm{RD}$ fibre for the constant $\phi_{2}=0^{\circ}$ section, which is maximum at $\{001\}<100>$ and also decreases progressively towards $\{011\}<100>$. On the contrary, in the copper-type rolling texture, the brass (Bs) component $\{011\}<112>$ predominates over the S-component $\approx\{123\}<634>$ and the copper $(\mathrm{Cu})$ component $\{112\}<111>$ with the later one as minor ingredient of the rolling texture. The orientations of this rolling texture are distributed along an orientation tube which is inclined to constant $\phi_{2}$ sections and extends from $\{011\}<112>$ at $\phi_{1}=35^{\circ}, \phi=45^{\circ}$ and $\phi_{2}=0^{\circ}$ to $\{112\}<111>$ at $\phi_{1}=39^{\circ}, \phi=66^{\circ}$ and $\phi_{2}=27^{\circ}$, or symmetrically equivalent and more convenient, from $\{112\}<111>$ at $\phi_{1}=90^{\circ}, \phi=35^{\circ}$ and $\phi_{2}=45^{\circ}$ to $\{011\}<112>$ at $\phi_{1}=35^{\circ}, \phi=45^{\circ}$ and $\phi_{2}=90^{\circ}$. The skeleton line of this tube also includes the orientation $\approx\{123\}<634>$ at $\phi_{1}=59^{\circ}, \phi=37^{\circ}$ and $\phi_{2}=63^{\circ}$ and has its $\{110\}$ fibre axis inclined about $60^{\circ}$ from ND towards RD $\left(<110>60^{\circ} \mathrm{ND}\right)$. The distribution of orientation densities along $<110>60^{\circ} \mathrm{ND}$ fibre has been shown in Figure 9. This figure also indicates clearly that the density is maximum at $\{011\}<112>$ and minimum at $\{112\}<111>$. The texture index calculated at the central layer was 3.7 .

Annealed Hot Band (AHB)

\section{Microstructure}

Upon annealing the $\mathrm{HB}$ at $1353 \mathrm{~K}$, the grains in the surface as well as in the central layers grew in size and the average grain size values measured in the rolling plane sections at these layers were about $17 \mu \mathrm{m}$ and $20 \mu \mathrm{m}$, respectively. Figure 10(a) and 


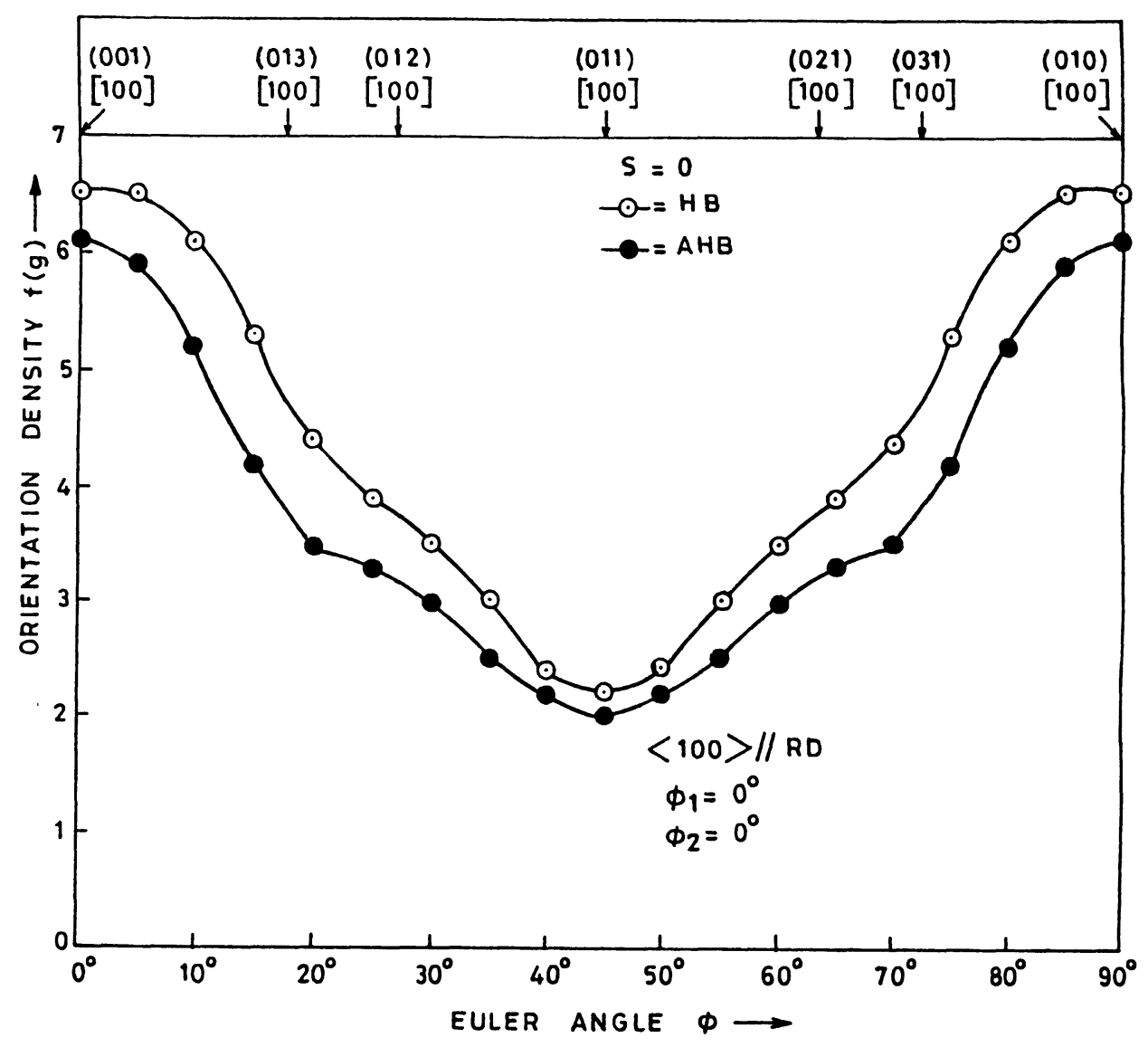

Figure 8 Orientation densities of the recrystallised texture components of $<100>/ /$ RD fibre at the centre $(S=0)$ level of the hot band and the annealed hot band.

(b) depicts the microstructures of the longitudinal sections of the AHB at $S=1$ and $S=0$ levels respectively. The presence of coarse grains originating from the pre-existing grain boundaries along with some annealing twins, in contrast to the microstructures of the HB [Figure 1 (a) and (b)], is the most interesting features of the microstructures observed in the optical microscope for the surface and the central layers of the AHB. The average hardness values measured near the surface and the central layers of the AHB were about $174 \mathrm{HV}_{5}$ and $200 \mathrm{HV}_{5}$, respectively.

Figure 11(a) and (b) reveals the bright field images of the TEM features observed in the central layer of the AHB. Marked lateral growth also occurred in some of the recovery twins [Figure 11a)]. Furthermore, clustering of twins is also apparant. The SADP taken from the clustered twin regions was of $\{011\}<112>$ type. On the other hand, Figure 11(b) illustrates the growth of a recovery twin into a full grown annealing twin and the associated SADP was, again, of $\{011\}<112>$ type. In almost every case, the twins were parallel to the rolling direction trace in the rolling plane foils examined. 


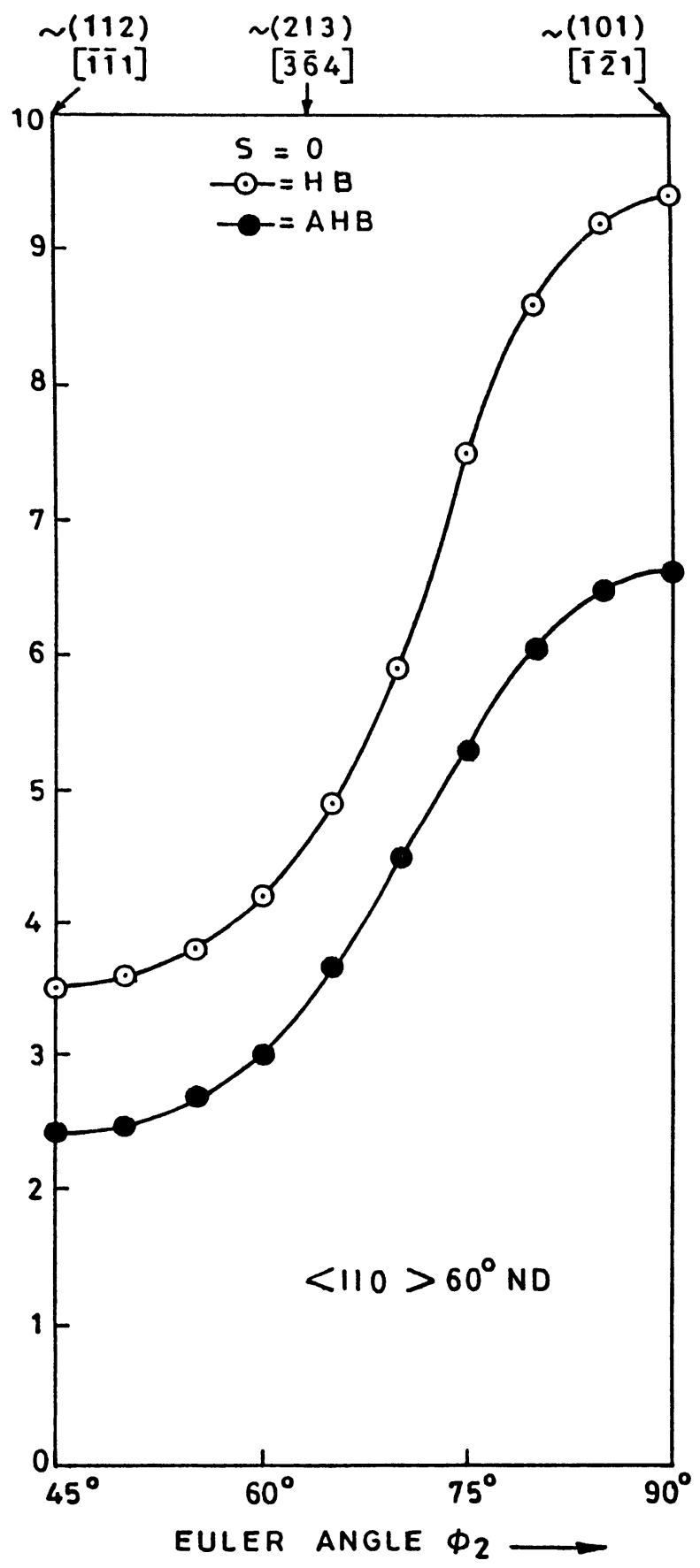

Figure 9 Orientation densities along the skeleton line of $<110>60^{\circ} \mathrm{ND}$ fibre at the centre $(\mathrm{S}=0)$ level of the hot band and the annealed hot band. 

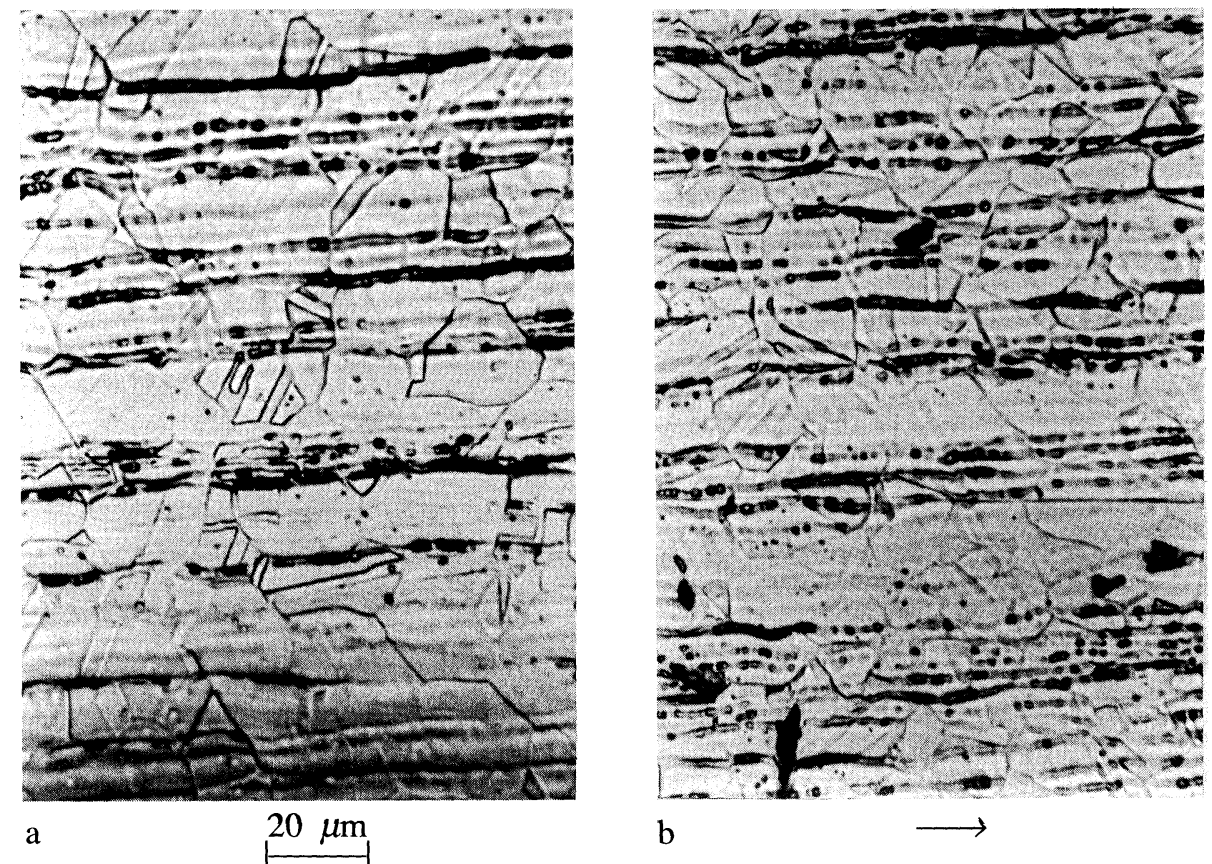

Figure 10 Optical micrographs of longitudinal section of the annealed hot band: (a) near surface (b) at centre: arrow parallel to rolling direction.

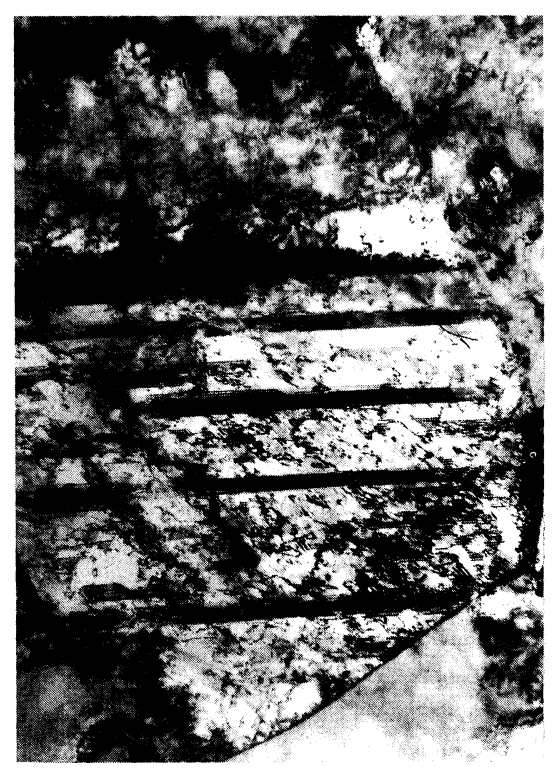

a

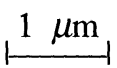

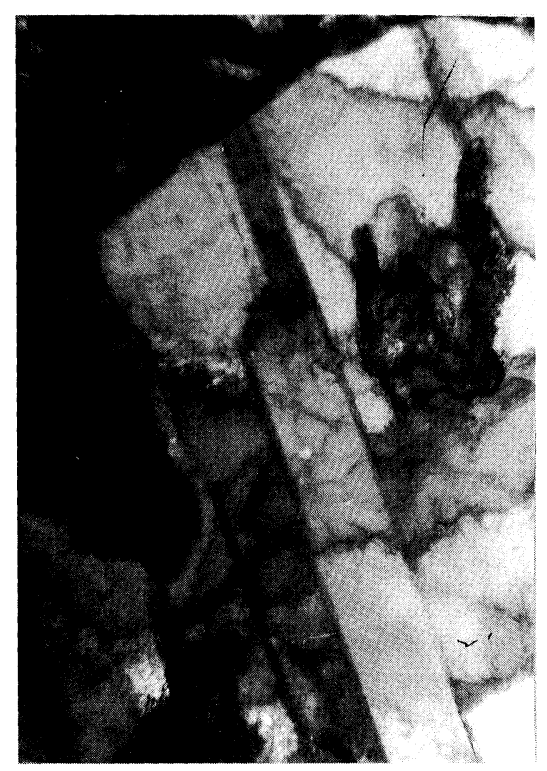

b

Figure 11 Transmission electron micrographs of the central layer of the annealed hot band: (a) bright field image of recovery twins (b) bright field image of annealing twin. 


\section{Texture}

Figure 12 exhibits the ODF of crystallites for the surface layer $(S=1)$ of the AHB in constant $\phi_{1}$ sections and the maxima for the orientations observed in this ODF are given in Table 1. All prominent orientations for the surface layer of the AHB in constant
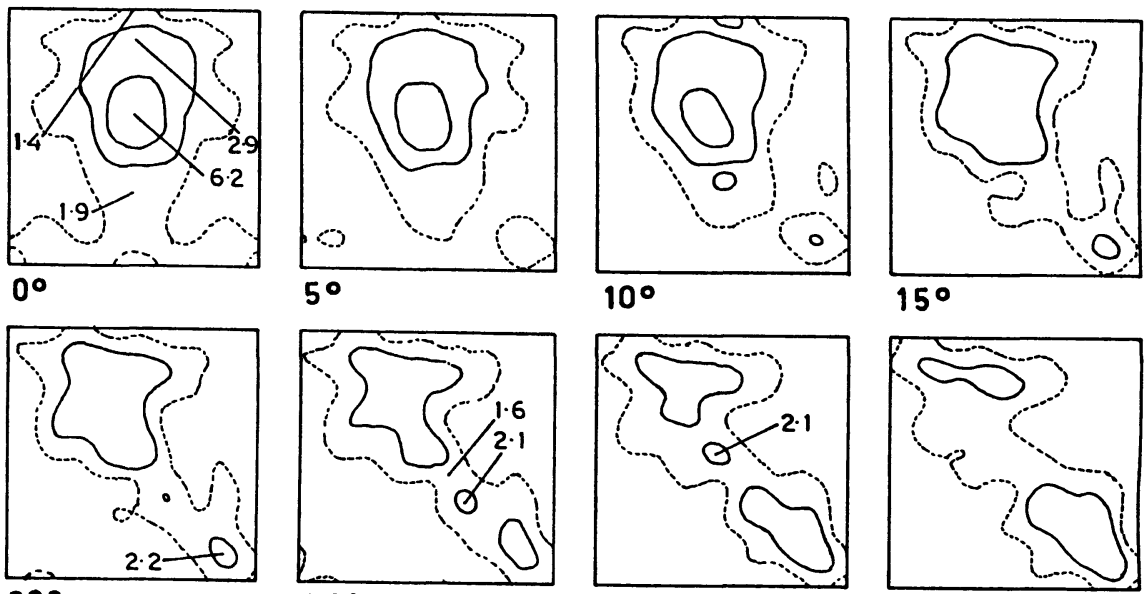

$15^{\circ}$
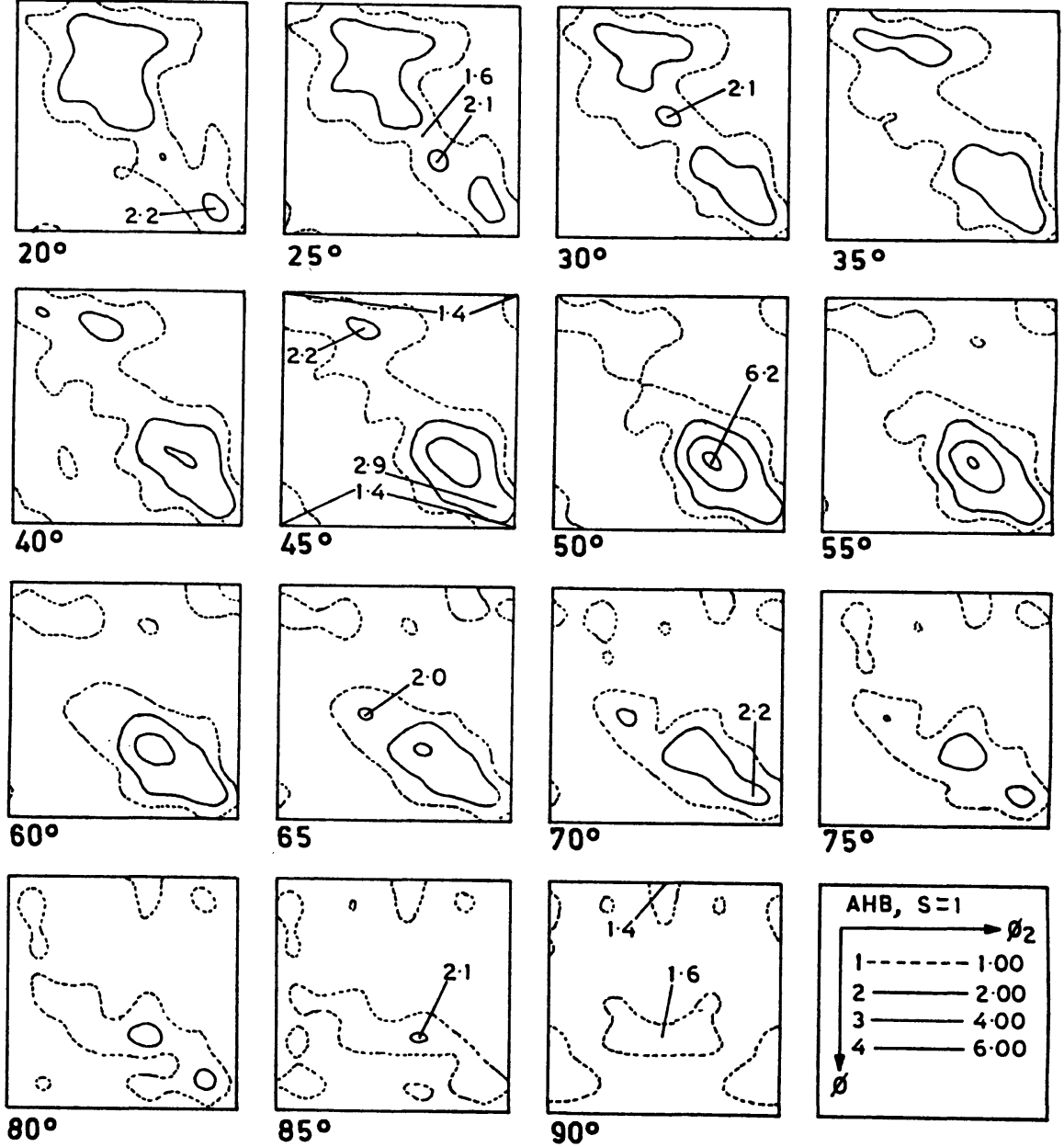

Figure 12 ODF for surface $(S=1)$ level of the annealed hot band in constant $\varnothing_{1}$ sections. 
$\phi_{2}=45^{\circ}$ section is given in Figure 13 . It is clearly evident from Figures 12 and 13 that the surface texture components are distributed, like HB surface textures, along the two limited orientation tubes whose fibre axes are $<110>/ / \mathrm{RD}$ and $<110>30^{\circ} \mathrm{ND}$. The maximum density is observed again at the orientation $\left\{\begin{array}{lll}7 & 7 & 12\end{array}\right\}<110>$ and all other orientations, observed in the $\mathrm{HB}$ surface texture, are also present at the surface layer of the AHB. The distributions of orientation densities along these orientation fibres are also shown in Figures 5 and 6 respectively. The texture index $J$ determined near the surface layer was 1.9. In comparison with the surface texture components of the $\mathrm{HB}$, a strong scattering of all prominent orientations along $\phi_{1}, \phi$ and $\phi_{2}$ directions has been observed. Furthermore, upon annealing the HB, the texture index as well as the orientation densities of all the texture components of $<110>/ / \mathrm{RD}$ and $<110>30^{\circ} \mathrm{ND}$ fibres have decreased considerably (Figures 5 and 6).

The ODF of crystallites for the central layer $(S=0)$ of the AHB is presented in Figure 14 in constant $\phi_{2}$ sections and the maxima for the orientations observed in this ODF are given in Table 2. Like the HB centre texture, here again, the texture at the centre of the AHB is comprised of the orientation elements of the recrystallisation texture and the copper-type rolling texture. The most essential features of this recrystallisation texture are the appearance of two new orientations $\{011\}<111>$ and $\{011\}<411>$ along with the orientation elements $\{001\}<100>,\{013\}<100>,\{012\}<100>$ and $\{011\}<100>$. Further, the scattering of the cube orientation $\{001\}<100>$ at $\phi_{1}=\phi=\phi_{2}=0^{\circ}$ towards the Goss orientation $\{011\}<100>$ at $\phi_{1}=0^{\circ}, \phi=45^{\circ}$ and $\phi_{2}=0^{\circ}$, present in the HB, is still persisting in the AHB but in slightly reduced strength (Figure 14). The coppertype texture is characterised by the presence of orientations $\{011\}<112>, \approx\{123\}<634>$ and $\{112\}<111\rangle$. The first one is major and the other two are minor elements. The observed orientation $\{139\}<956>$ is nearer to the orientation $\{123\}<634>$. Like the scattering of the orientations observed in the surface texture of the AHB, these orientation elements at the centre also exhibit a scattering in $\phi_{1}, \phi$ and $\phi_{2}$ directions. Upon annealing the HB, the strength of all these copper - type texture components has decreased but still the components are distributed along the limited orientations tube with its fibre axis $<110>60^{\circ} \mathrm{ND}$ inclined about $60^{\circ}$ from ND towards RD. Figure 9 also shows the distribution of orientation densities along this $<110>60^{\circ} \mathrm{ND}$ fibre. The annealing of
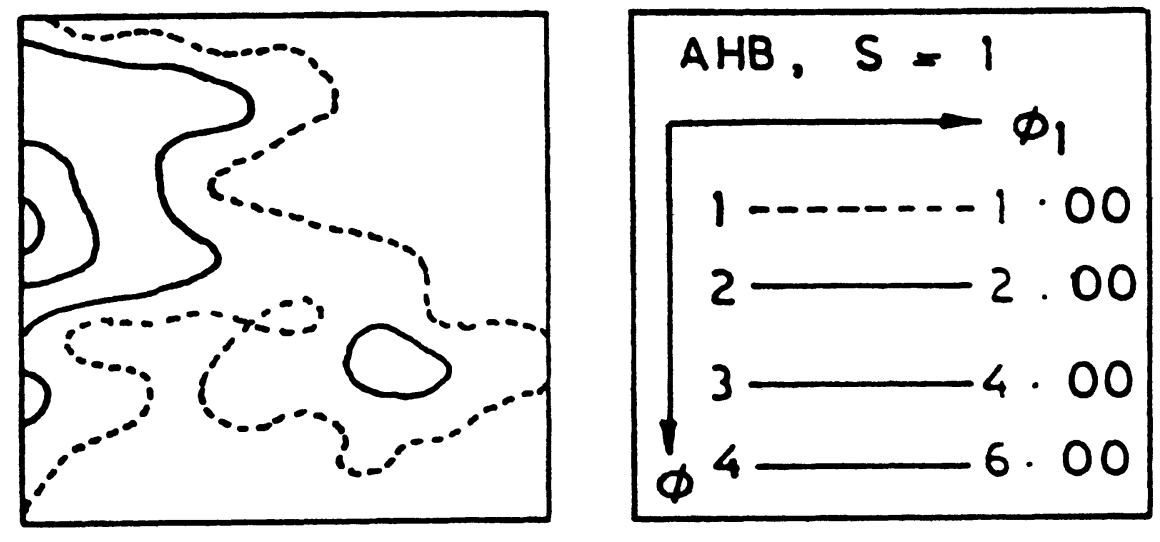

Figure 13 Section $\varnothing_{2}=45^{\circ}$ of the ODF for surface $(S=1)$ level of the annealed hot band. 
the HB has caused more decrease in the orientation density of $\{011\}<112>$ component as compared with those of $\approx\{123\}<634>$ and $\{112\}<111>$ components. The measured texture index at the centre was 2.7 .
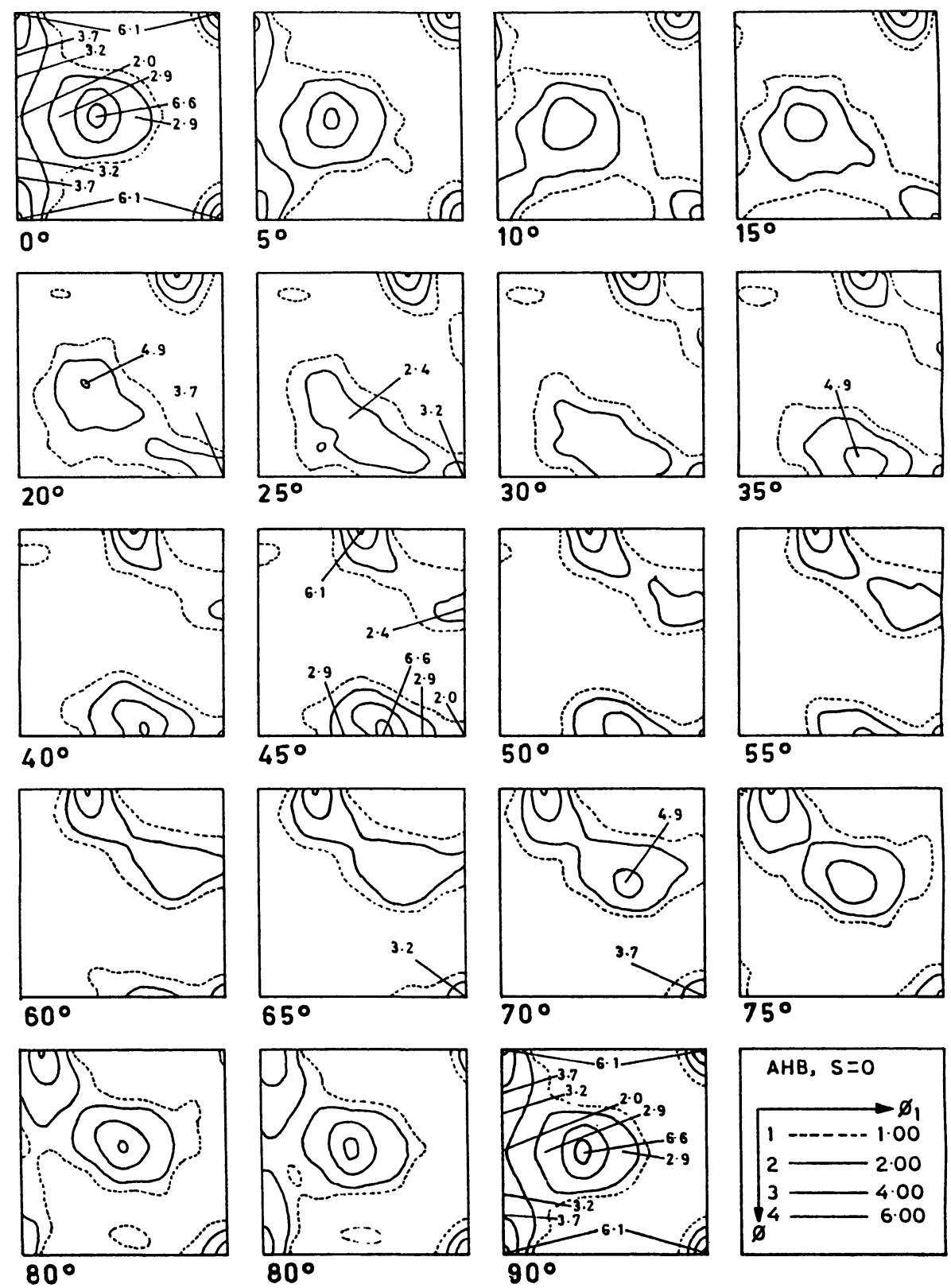

Figure 14 ODF for centre $(S=0)$ level of the annealed hot band in constant $\varnothing_{2}$ sections. 


\section{DISCUSSION}

\section{Evolution of Hot Band Texture}

During hot rolling, the surface and the sub-surface layers undergo a shear strain deformation which leads to high dislocating density, whereas the central layers are subjected to plain strain deformation similar to cold rolling. Depending upon the conditions of rolling (i.e. shear strain or plain strain) one obtains shear or rolling textures in deformed material, respectively. In case of austenitic stainless steel, continuously cast slabs are hot rolled to strip in single phase $(\gamma)$ region. This hot rolling is accomplished in more number of deformation steps and the total degree of reduction is very high. The last few steps determine, to a great extent, the microstructural and textural states of the grains through the thickness of the strip. These states of the grains also depend upon the temperature of deformation and the final strip thickness. Furthermore, because of water spraying and contact with the rolls, the surface layers experience a comparatively lower temperature and thus at the surface, dynamic recovery is lowered and the stored deformation energy is higher than in the central layers. In the last few passes, these conditions lead to dynamic recrystallisation in the surface layers and dynamic recovery and/or dynamic recrystallisation in the central layers.

In view of the above physical processes (i.e. deformation, dynamic recovery or dynamic recrystallisation) occurring during hot rolling, it can be inferred that the grains of the surface and the sub-surface layers of the HB are dynamically fully recrystallised as evident from the presence of equiaxed grains mostly originating from the pre-existing grain boundaries [Figure 1(a)]. Further, the appearance of the surface texture components distributed along two limited orientation tubes represented by $<110>/ / \mathrm{RD}$ and $<110\rangle$ $30^{\circ} \mathrm{ND}$ fibres (Figure 4 ) with a maxima at $\approx\{112\}<110>$ reveals that these texture components are formed due to the shear strain caused by the frictional force between the strip surface and the working rolls and they are essentially the elements of shear texture. In fact, the orientations $\{001\}<110>,\{112\}<110>$ and $\left\{\begin{array}{lllll}11 & 11 & 8\end{array}\right\}<4 \quad 4 \quad 11>$ are the ones predicted theoretically as stable orientations by Dillamore and Katoh (1974a) under the action of imposed shear. Additionally, the orientation $\{111\}<110>$ becomes stable by permitting shear parallel to the rolling plane along transverse direction (Dillamore and Katoh, 1974b). Dillamore and Katoh (1974b) has further shown, in an elegant fashion, that these stable texture components and the spread range between them (i.e. $<110>/ / \mathrm{RD}$ and $<110>30^{\circ} \mathrm{ND}$ fibres) are best suited for the formation of recrystallised nuclei by subgrain growth and also grain boundary nucleation, because these orientations belong to the regions of uniform orientation where slip rotations usually converge. Hence, all these microstructural and textural evidences indicate that some processes of simultaneous shearing and dynamic recrystallisation by subgrain growth and grain boundary nucleation are occurring near the surface and the sub-surface regions as the austenitic stainless steel is hot rolled.

On the other hand, for the central layer of the $\mathrm{HB}$, the microstructural feature [Figure 1(b)] reveals the presence of equiaxed grains in some bands, while the ODF evidence (Figure 7) indicates the appearance of cube orientation $\{001\}<100\rangle$ and the other RD rotated cubes in between the cube position and the Goss position. These orientations are elements of recrystallisation texture and are divergent orientations (Dillamore and Katoh, 1974b). As discussed by Singh, Ramaswamy and Suryanarayana (1991) the origin of cube orientation and the $\mathrm{RD}$ rotated cubes at the centre of the $\mathrm{HB}$ has been attributed to a process of dynamic recrystallisation controlled by oriented nucleation (Dillamore 
and Katoh, 1974b) of the orientations of divergent zones at the transition bands developed in the grains of $\{112\}<111>$ orientation and by oriented growth (Virnich et al., 1978; Lücke, 1984) of the cube grains at the expense of $\approx\{112\}<111>$ and $\approx\{123\}<634>$. The ODF result (Figure 9), indicating a very low strength of $\approx\{112\}<111>$ and an intermediate strength of $\approx\{123\}<634>$ in comparison with the very high strength of $\{011\}<112>$, confirms that it is the $\mathrm{Cu}$-component which decreases first in favour of cube orientation on recrystallisation and these cube grains grow at the expense of $\approx\{123\}<634>$ because of a good $40^{\circ}<111>$ orientation relationship. Further, the grains of Bs-orientation possess a poor $40^{\circ}<111>$ relationship with cube grains, they are consumed at a much lower rate. On the contrary, the formation of recovery twins (Figure 2) having orientation $\{011\}<112>$ in the grains of Bs-component $\{011\}<112>$ shows that the Bs-oriented grains are dynamically recovered through the operation of processes pertaining to the growth accident (Carpenter and Tamura, 1926) and to the growth stimulation (Burgers and May, 1948) theories. Since, the HB strip was finished at lower temperature $(1173 \mathrm{~K})$ so sufficient time was not available for the complete growth of cube grains at the expense of the remaining grains of deformation texture and thus a partially recrystallised structure, consisting of some grains of recrystallised cube orientation and the others of $\{011\}<112>$ in recovered state, is produced at the central layers of the HB.

\section{Development of Annealing Texture}

In the past, many studies on annealing texture development have dealt upon the mechanism of formation, the morphology and the orientation of the first formed nuclei and grains. In many cases, these nuclei and grains are not significant to the final annealing texture but may be significant in other cases. Thus any successful theory of annealing texture development must take into account not only the final texture but also the microstructure of the annealed strip. The most striking feature of the microstructure [Figure 10(a)] of the present investigation is the presence of a considerable volume of twinned grains and of the migration of the pre-existing boundaries at surface layers of the AHB. Further, the evidences, such as the increase in the grain size (i.e. from about $7 \mu \mathrm{m}$ to $20 \mu \mathrm{m}$ ) and the substantial softening (i.e. drop from about $235 \mathrm{HV}_{5}$ and $174 \mathrm{HV}_{5}$ ), indicate the occurrence of the normal grain growth process in the surface layers as the HB is annealed for short time. The present ODF results (Figures 12 and 13) of the surface texture of the AHB show the presence of the shear texture components distributed along the two limited orientation tubes (i.e. $<110>/ / \mathrm{RD}$ and $<110>30^{\circ} \mathrm{ND}$ fibres) with $\approx\{112\}<110>$ as the major element of the texture. Furthermore, the decrease in the strength of the texture from a value $(\mathrm{J}=3.0)$ obtained near the surface of the HB to a value $(\mathrm{J}=1.9)$ determined near the surface of the AHB, reveals that the surface grains, after annealing, are much more randomised with respect to that of the HB. The other interesting feature of these ODF results are the presence of isotropic scattering of the orientations of the two limited fibres along the Euler axes $\phi_{1}, \phi$ and $\phi_{2}$ and the reduction in the orientation densities of the fibres $\left(<110>/ / \mathrm{RD}\right.$ and $\left.<110>30^{\circ} \mathrm{ND}\right)$ as given in Figures 5 and 6 . No new orientations having a twin relationship with the matrix orientations have appeared on the surface of the AHB.

The relationship between the twinned grains, their orientation and the final annealing texture obtained at the surface layer, after the given annealing treatment, is not clear. The orientation relationship between a twin (of first order) and its origin is a $180^{\circ}$ 
rotation about the twinning plane normal. In F.C.C. crystals, the twinning plane is a $\{111\}$ plane. Since the majority of the surface grains of the HB have $\approx\{112\}<110\rangle$ orientation, it is most likely that this orientation undergoes twinning operation during the annealing treatment. Further, one of the first order twin orientations of $\{112\}<110>$ is the same $\{112\}<110\rangle$. Thus it may be concluded that the twined grains, at the surface and the sub-surface layers, have also $\{112\}<110>$ orientation. The origin of $\{112\}<110>$ oriented twinned grains may be attributed to the formation of recovery twins in the microband regions of the hot deformation structure having $\approx\{112\}<110>$ orientation and to their growth during subsequent annealing (Huber and Hatherly, 1980; Wakefield and Hatherly, 1983). It is also possible that some recrystallised grains of $\approx\{112\}<110\rangle$ orientation, mostly nucleated at the grain boundaries, grow by the migration of the boundaries and undergo twinning operation according to the theory of growth accident (Carpenter and Tamura, 1926) combined with that of growth stimulation (Burgers and May, 1948), because the probability of growth accident is very high when the orientation of the matrix is nearer to the twin of the growing grains. The similar phenomenon, as happening in the case of $\approx\{112\}<110>$ orientation, is also prevailing with the twinned grains of $\approx\{111\}<110>$ orientation, while the twins of the $\approx\{001\}<110>$ oriented grains have different orientations and have not been observed in the surface texture. Hence the microstructural evidences such as the annealing twins, the enlarged grains and the migration of the pre-existing grain boundaries as well as the textural evidences suggest that the some surface grains grow by the migration of the grain boundaries and twin to the orientations, which are same as the recrystallised matrix orientations such as $\approx\{112\}<110\rangle$ and $\approx\{111\}<110>$, during the induced growth process as per the growth accident and the growth stimulation theories.

On the other hand, the most attractive features of the microstructure at the central layers of the AHB are the presence of twins, recrystallised grains and the migrated grain boundaries [Figure 10(b)]. The marked lateral growth and clustering of some recovery twins are also apparant in the microstructure [Figure 11(a)]. The present results, further, show that the volumes associated with the recovery twins [Figure 11(a)] and the annealing twins [Figure 11(b)] have the $\{011\}<112>$ orientation. The other evidences i.e. the increased grain size $(20 \mu \mathrm{m})$ and the extensive softening (decrease from 269 $\mathrm{HV}_{5}$ to $200 \mathrm{HV}_{5}$ ) in the central layer of the AHB, denote that the grains have been completely recrystallised. The ODF result (Figure 14) indicates the presence of orientation elements of recrystallised texture distributed along $<100>/ / \mathrm{RD}$ with a maximum in density at $\{001\}<100>$ as well as of copper-type texture distributed along $<110>60^{\circ} \mathrm{ND}$ fibre with $\{011\}<112>$ as a major component and $\approx\{123\}<634>$ and $\approx\{112\}<111>$ as minor components. The other essential features of this ODF are the isotropic scattering of orientations observed along the Euler axes $\phi_{1}, \phi$ and $\phi_{2}$ and the reduction in the orientation density of $\langle 110\rangle 60^{\circ} \mathrm{ND}$ fibre, particularly in that of Bscomponent $\{011\}<112>$ (Figure 9). The given annealing treatment has also randomised the texture present at the centre of the HB. This randomisation is substantiated by the fact that the texture strength $(J=3.7)$ of the HB has decreased to a value $(J=2.7)$, after annealing the HB. Further, the appearance of the orientations such as $\{011\}<111>$ and $\{011\}<411>$ is most interesting. Dillamore and Katoh (1974b) also reported that during annealing of F.C.C. metals and alloys, grain boundary nucleation occurs for the orientations lying in the convergent region i.e. $\{011\}<111>$ and $\{011\}<411>$ which are closer to the stable deformation texture component $\{011\}<112>$. The observed orientations $\{011\}<111>$ and $\{011\}<411>$ at the central layer of the AHB are about $20^{\circ}$ and $16^{\circ}$ away from the orientation $\{011\}<112>$ rotated about $<110>/$ ND axis, 
respectively. Furthermore there is a spread range (about $\pm 20^{\circ}$ ) of the orientation $\{011\}<112>$ along $<110>/ / \mathrm{ND}$ axis at the centre of the HB. The densities of the recrystallised components of $<100>/ / \mathrm{RD}$ fibre of the AHB (Figure 8) remain more or less the same as those obtained near the centre of the HB. None of twin orientations of the cube texture $\{001\}<100>$ have been detected in the present ODF results of the AHB.

From the above mentioned microstructural and textural features, it can be inferred that the origin of the twinned grains are associated with the formation and the growth of the recovery twins which mostly form in the microband regions of the hot deformed structure (Huber and Hatherly, 1980; Wakefield and Hatherly, 1983) and then grow during the annealing treatment. It is interesting to note that all the three i.e. recovery twins, annealing twins and the matrix regions have the same orientation i.e. $\{011\}<112>$. Furthermore, the migration of the pre-existing grain boundaries as well as the appearance of $\{011\}<111>$ and $\{011\}<411>$ orientations, at the central layers of the AHB, further concludes that the nuclei of convergent orientations such as $\{011\}<111>,\{011\}<411>$ and $\{011\}<112>$ etc. form at the grain boundaries within the spread range of coppertype texture particularly of $\{011\}<112>$ component and then grow by the migration of the boundaries. Some of these recrystallised nuclei such as $\{011\}<112>$ undergo twinning operation as per the growth accident (Carpenter and Tamura, 1926) and the growth stimulation (Burgers and May, 1948) theories, as one of the first order twins of $\{011\}<112>$ orientation is of the same type i.e. $\{011\}<112>$ Thus it can be construed that the given annealing treatment has led to the complete recrystallisation of the grains of the central layers of the HB.

\section{CONCLUSIONS}

i) The surface grains of the commercially produced austenitic stainless steel hot band are completely recrystallised, whereas some grains are recrystallised and the others are in the recovered state, in the central layers.

ii) The surface grains of the hot band possess the orientation elements of the shear texture distributed along two limited orientation tubes (i.e. $<110>/ / \mathrm{RD}$ and $<110>$ $30^{\circ} \mathrm{ND}$ fibres) with $\approx\{112\}<110>$ as the major component and these texture components are formed, during hot rolling, by the simultaneous action of the shear force and the process of dynamic recrystallisation by subgrain growth and grain boundary nucleation.

iii) The texture, in the central layer of the hot band, is composed of orientation elements of the recrystallisation texture distributed along $<100>/ / \mathrm{RD}$ fibre and those of the copper-type texture, along $<110>60^{\circ} \mathrm{ND}$ fibre with $\{001\}<100>$ and $\{011\}<112>$ as major components respectively. The origin of the cube orientation and the other RD rotated orientations has been attributed to the oriented nucleation of the divergent zone orientations in the transition bands developed in the grains of $\{112\}<111>$ and also to the oriented growth in the matrix grains of $\{112\}<111>$ and $\approx\{123\}<634>$, while the grains having $\{011\}<112>$ are recovered through the formation of the recovery twins.

iv) The short time annealing of the hot band has led the surface and the sub-surface grains to grow by migration of the pre-existing grain-boundaries and has also caused a complete recrystallisation to the grains of central layers. A considerable amount of annealing twins has also been formed, both in the surface and the central layers 
of the hot band, by the growth of the recovery twins as well as by the growth of the grains mostly nucleated at the grain boundaries as per the growth accident and the growth stimulation theories.

v) Like the hot band, the surface texture of the annealed hot band is consisted of grains having the orientation elements of the shear texture distributed along the $<110>/ / \mathrm{RD}$ and $<110>30^{\circ} \mathrm{ND}$ fibres with $\approx\{112\}<110>$ as the major component, while the texture, in the central layers, is composed of the elements of recrystallisation texture (i.e. cube $\{001\}<100>$ and $<100>/ / \mathrm{RD}$ rotated cubes) and those of copper-type texture (i.e. $<110>60^{\circ} \mathrm{ND}$ ) with the major component as $\{011\}<112>$. The orientation of the twinned grains, in the surface and the central layers of the annealed hot band, are mostly $\approx\{112\}<110>$ and $\{011\}<112>$, respectively. The grain boundary nuclei, formed as a result of the short time annealing, had led to the appearance of the orientations $\{011\}<111>$ and $\{011\}<411>$ in the central layers of the annealed hot band.

\section{Acknowledgements}

The author would like to express his gratitude to the management of RDCIS, SAIL, Ranchi, for according the permission to publish this work.

\section{References}

Beck, P. A. (1954). Phil. Mag., 3, 245.

Beck, P. A. and Hu, H. (1966). Recrystallisation, Grain Growth and Textures, Ed. H. Margolin, Metals Park Ohi.

Bunge, H. J. (1982). Texture Analysis in Materials Science, Butter Worths, London.

Bunge, H. J. (1991). Proc. ICOTOM 9 (1990) Published in Textures and Microstructures; Vol. 14-18.

Bunge, H. J. (1993). Proc. ICOTOM 10, Trans. Tech Publications, Switzerland.

Brakman, C. M., Jongenburger, P. and Mittemeijer, E. J. (1984). Proc. ICOTOM 7, Society for Materials Science, Netherlands, Noordwijkerhout.

Burgers, W. G. (1949). Physica, 15, 92.

Burgers, W. G. and Louwerse, P. C. (1931). Z. Phys., 61, 605.

Burgers, W. G. and May, W. (1948). Metalen, 2, 172.

Burgers, W. G. and Tiedema, T. J. (1953). Acta met., 1, 234.

Burgers, W. G. and Tiedema, T. J. (1957). Metalen, 12, 1.

Carpenter, H.C.H. and Tamura, S. (1926). Proc. Roy. Soc., London, 113A, 161.

Davies, G. J., Dillamore, I. L., Hudd, R. C. and Kallend, J. S. (1975). Texture and the Properties of Materials, The Metals Society, London.

Dillamore, I. L. and Katoh, H. (1974a). Metal Sci., 8, 21.

Dillamore, I. L. and Katoh, H. (1974b). Metal Sci., 8, 73.

Dillamore, I. L. and Roberts, W. T. (1965). Met. Rev., 10, 271.

Gottstein, G. and Lücke, K. (1978). Texture of Materials, Vol. 1 and 2, Springer Verlag, Berlin.

Grewen, J. (1971). Recrystallisation of Metallic Materials, Ed. F. Haessner, Rieder Verlag, Stuttgart.

Grewen, J. and Wassermann, G. (1969). Texture in Research and Practice, Springer Verlag, Berlin.

Guttman, V. (1973). Z. Metallkde., 64, 95.

Huber, J. and Hatherly, M. (1979). Metal Sci., 13, 655.

Huber, J. and Hatherly, M. (1980). Z. Metallkde., 71, 15.

Hutchinson, W. B. (1974). Metal Sci., 8, 185.

Kallend, J. S. and Gottstein, G. (1988). Proc. ICOTOM 8, The Metallurgical Society, AIME, Warrendale.

Karp, J., Gorczyca, S., Bunge, H. J., Pospiech, J. and Dabrawoski, W. (1971). Quantitative Analysis of Textures, The Society of Polish Metallurgical Engineers, Cracow.

Kern, R. and Bergmann, H. W. (1978). Proc. ICOTOM 5, Vol.1, Eds. G. Gottstein and K. Lücke, Springer Verlag, Berlin, 139.

Lücke, K. (1974). Can. Met. Quart., 13, 261. 
Lücke, K. (1984). Proc. ICOTOM 7, Eds. C.M. Brakman, P. Jongenburger and E.J. Mittemiejer, Society for Materials Science, Netherlands, Noordwijkerhout, 195.

Lücke, K., Pospiech, J., Virnich, K. H. and Jura, J. (1981). Acta Met., 29, 167.

Matthies, S. (1979). Phys. Stat. Sol., Vol. (b) 92, P.K. 135.

Nagashima, S. C. (1981). Proc. ICOTOM 6, Vol. 1 and 2, The Iron and Steel Institute of Japan, Tokyo.

Penelle, R. (1973). 3e Colloque Europeen Sur les Textures de Déformation et de Recrystallisation des Métaux et leur Applications Industrielles, Pont-ā-Mousson.

Singh C. D. (1989). Ph. D. Thesis, Banaras Hindu University, India.

Singh C. D., Ramaswamy, V. and Suryanarayana, C. (1991). Textures and Microstructures, 13, 227.

Schulz, L. G. (1949). J. Appl. Phys., 20, 1030.

Verberaak, C. A. (1958). Acta Met., 6, 580.

Verberaak, C. A. (1981). Proc. ICOTOM 6, Vol. 1, Ed. S.C. Nagashima, The Iron and Steel Institute of Japan, Tokyo, 98.

Virnich, K. H., Köhlhoff, G. D., Lücke, K. and Pospiech, J. (1978). Proc. ICOTOM 5, Vol. 1, Eds. G. Gottstein and K. Lücke, Springer Verlag, Berlin, 347.

Wakefield, P. T. and Hatherly, M. (1983). Metal Sci., 17, 55. 